\title{
Pengetahuan Keluarga Berperan terhadap Keterlambatan Kedatangan Pasien Stroke Iskemik Akut di Instalasi Gawat Darurat
}

\section{The Effect of Family Knowledge on Acute Ischemic Stroke Patients' Arrival Delay at Emergency Department}

\author{
Dewi Rachmawati, Sri Andarini, DK Ningsih \\ ${ }^{1}$ Program Studi Keperawatan Blitar Politeknik Kesehatan Kemenkes Malang \\ ${ }^{2}$ Laboratorium IImu Kesehatan Masyarakat Fakultas Kedokteran Universitas Brawijaya Malang \\ ${ }^{3} J u r u s a n$ Keperawatan Fakultas Kedokteran Universitas Brawijaya Malang
}

\begin{abstract}
ABSTRAK
Keberhasilan tindakan dan peningkatan outcome pada stroke sangat bergantung pada kecepatan pasien dibawa ke instalasi gawat darurat namun sebagian besar pasien stroke iskemik akut datang terlambat. Tujuan penelitian ini adalah untuk mengetahui pengaruh pengetahuan tentang faktor risiko dan peringatan gejala stroke terhadap keterlambatan kedatangan pasien post serangan stroke iskemik akut di instalasi gawat darurat di RSUD Ngudi Waluyo Wlingi. Desain penelitian yang digunakan adalah cross sectional. Pengumpulan data dilakukan dengan memberikan kuesioner pada anggota keluarga pasien stroke iskemik akut yang dipilih secara consecutive sejumlah 58 orang dengan pertimbangan mengetahui dan terlibat langsung membawa pasien ke instalasi gawat darurat. Analisis data dilakukan dengan menggunakan analisis univariat dan regresi linier berganda untuk mengetahui pengaruh pengetahuan terhadap keterlambatan. Hasil penelitian menunjukkan rata-rata skor pengetahuan responden adalah 8,55 \pm SD 4,551 dan koefisien korelasi $-0,303(p=0,041)$. Dapat disimpulkan bahwa pengetahuan tentang faktor risiko dan peringatan gejala stroke menurunkan keterlambatan kedatangan pasien post serangan stroke iskemik akut.
\end{abstract}

Kata Kunci: Faktor risiko, keterlambatan, peringatan gejala stroke

\begin{abstract}
Action success and increased outcome in stroke depend largely on how immediate the patient is being taken to the emergency department, but most acute ischemic stroke patients are late. The purpose of this study was to determine the effect of knowledge on risk factors and warning symptoms of stroke on patient arrival delay in post-acute ischemic stroke attack at emergency installation in Ngudi Waluyo Wlingi General Hospital. The research design used was cross sectional. The data were collected by giving questionnaires to 58 consecutively selected people who were family members of acute ischemic stroke patients by considering knowing and being involved directly in bringing patients to the emergency department. Data analysis was done by using univariate analysis and multiple linear regression to know the effect of

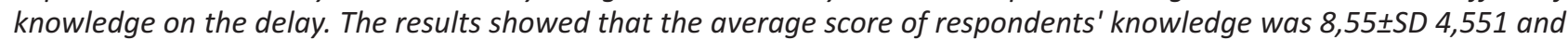
correlation coefficient was $-0,303(p=0,041)$. It can be concluded that knowledge on risk factors and warning symptoms of stroke decreases patient delayed arrival in post-stroke ischemic attack.
\end{abstract}

Keywords: Delayed hospital arrival, risk factor, warning symptoms of stroke.

Korespondensi: Dewi Rachmawati. Program Studi Keperawatan Blitar Politeknik Kesehatan Kemenkes Malang, Jl. Dr. Sutomo No. 46 Blitar, Tel.082131667448Email:rachmawati_dewi13@yahoo.com

DOI: http://dx.doi.org/10.21776/ub.jkb.2017.029.04.15 


\section{PENDAHULUAN}

Stroke merupakan kegawatan darurat medik yang menjadi salah satu penyebab kematian dan kecacatan terbanyak di dunia (1-2). Stroke membunuh 1 orang setiap 6 detik di dunia, dengan perkiraan 15 juta orang di dunia terserang stroke setiap tahunnya, 5 juta diantaranya meninggal dan 5 juta lainnya mengalami kecacatan permanen (3-5). Di negara berkembang salah satunya Indonesia, angka kejadian stroke semakin meningkat tajam. Indonesia termasuk salah satu negara dengan jumlah penderita stroke terbesar di dunia (6). Stroke ini menyumbang $11.8 \%$ dari total kematian di Indonesia dan merupakan penyebab utama kematian dan kecacatan yang diprediksi beban penyakit maupun ekonomi akibat stroke akan semakin meningkat pada tahun 2020 (7-9)

Besarnya angka kejadian, kematian dan kecacatan akibat stroke tersebut secara signifikan akan meningkatkan beban penyakit dan juga akan memperbesar biaya perawatan stroke yang dikeluarkan sehingga akan semakin meningkatkan beban keluarga maupun masyarakat secara keseluruhan (10). Salah satu upaya yang dilakukan untuk menurunkan beban akibat penyakit stroke tersebut adalah meningkatkan outcome dengan memberikan tindakan atau penanganan segera setelah serangan stroke serta memberikan pelayanan yang komprehensif selama perawatan di rumah sakit (11-13). Upaya tersebut penting terutama pada stroke iskemik akut yang berhubungan erat dengan kecacatan dan mempunyai prevalensi kejadian 10 kali lebih tinggi daripada stroke hemoragik $(12,14)$. Beberapa penelitian menyebutkan bahwa intervensi awal stroke iskemik akut sangat efektif ketika diberikan dalam waktu 3-5 jam setelah serangan. Efektivitas dari intervensi tersebut akan semakin menurun dengan semakin lamanya awal tindakan diberikan dari onset stroke (15-17). Keberhasilan tindakan dan peningkatan outcome sangat bergantung terhadap upaya meminimalkan keterlambatan untuk segera datang ke instalasi gawat darurat $(13,14,17,18)$.

Sebagian besar pasien stroke iskemik akut datang terlambat ke instalasi gawat darurat (18-20). Penelitian Pinzon di Yogyakarta menunjukkan hampir $87 \%$ pasien datang lebih dari 3 jam setelah serangan dan $46 \%$ diantaranya datang $>24$ jam setelah serangan (21). Demikian juga di RSUD Ngudi Waluyo Wlingi $80 \%$ pasien datang $>3$ jam setelah serangan. Keterlambatan ini merupakan masalah utama yang dihadapi pasien stroke iskemik akut untuk mendapatkan pertolongan segera $(13,22)$ yang salah satunya disebabkan kurangnya pengetahuan tentang faktor risiko dan peringatan gejala stroke. Studi sebelumnya menunjukkan hampir 60\% keluarga pasien tidak tahu tentang gejala stroke bahkan ada diantara keluarga tersebut yang mempunyai riwayat hipertensi, diabetes mellitus dan penyakit jantung namun tidak mengetahui bahwa riwayat penyakit tersebut merupakan faktor risiko yang menyebabkan stroke. Keluarga pasien tersebut juga tidak mengetahui jika stroke merupakan kondisi gawat darurat yang memerlukan pertolongan segera sehingga cenderung tidak segera membawa pasien ke rumah sakit atau mencari pertolongan.

Seseorang yang mempunyai pengetahuan kurang tentang faktor risiko dan peringatan gejala stroke serta tidak memahami konsep "time is brain" cenderung terlambat merespon stroke sebagai kondisi gawat darurat (12). Pinzon menyebutkan bahwa dari $74 \%$ pasien yang datang ke instalasi gawat darurat lebih dari 24 jam setelah serangan stroke mempunyai pengetahuan yang kurang tentang peringatan gejala stroke dan tidak memahami stroke merupakan kondisi gawat darurat yang memerlukan pertologan segera (21). Penelitian serupa di Nigeria juga menemukan hal yang sama (18). Jika seseorang tersebut mempunyai pengetahuan yang baik tentang faktor risiko dan peringatan gejala stroke akan menggunakan pengetahuan tersebut sebagai dasar terbentuknya tindakan dengan segera menghubungi layanan kegawatdaruratan untuk mendapatkan bantuan segera (23). Kecepatan pasien datang ke instalasi gawat darurat dan ketepatan perawatan dapat menurunkan risiko perburukan neurologis, meminimalkan kecacatan bahkan kematian $(24,25)$.

Di Instalasi Gawat Darurat (IGD) RSUD Ngudi Waluyo Wlingi stroke menduduki urutan kedua dalam 10 besar penyakit perbulan. Di rumah sakit ini stroke iskemik akut mempunyai jumlah lebih banyak daripada stroke hemorrhage dan $80 \%$ pasien datang lebih dari 3 jam sehingga memperburuk luaran pasien. Rekanalisasi dan kemungkinan perkembangan iskemik/infak dapat menyebabkan peningkatan/ perburukan neurologis yang sering terjadi pada jam-jam pertama setelah serangan sehingga merupakan waktu kritis untuk memberikan penanganan awal dengan segera $(26,27)$. Penelitian ini dilakukan untuk mengetahui pengaruh pengetahuan tentang faktor risiko dan peringatan gejala stroke terhadap keterlambatan kedatangan pasien post serangan stroke iskemik akut di IGD RSUD Ngudi Waluyo Wlingi.

\section{METODE}

Penelitian ini menggunakan desain cross sectional di Instalasi Gawat Darurat RSUD Ngudi Waluyo Wlingi pada 03 Mei -10 Juni 2016. Subjek penelitian adalah salah satu anggota keluarga (anak, suami, istri, cucu, saudara) dari semua penderita stroke iskemik akut yang mengetahui dan terlibat langsung membawa penderita ke IGD dalam 72 jam setelah serangan. Teknik pengambilan sampel yang digunakan adalah consecutive sampling. Kriteria inklusi penelitian adalah subjek yang berusia $\geq 18$ tahun, bersedia menjadi responden dan dalam kondisi sehat serta mampu berkomunikasi secara verbal maupun tertulis. Kriteria eksklusinya adalah keluarga pasien dengan kondisi di klinis dan hasil pemeriksaan CT-scan menunjukkan intracerebral hemorrhage, subaracnoid hemorrhage, TIA, keganasan atau neoplasma dan mempunyai riwayat stroke 6 minggu sebelumnya. Instrumen yang digunakan adalah kuesioner dengan 2 model pertanyaan. Pertanyaan terbuka berisi tentang definisi dan organ yang terkena stroke. Pertanyaan tertutup menggunakan modifikasi Stroke Recognition Questionnaire (SQR) diadaptasi dari Ennen (28). Penilaian kuesioner untuk pertanyaan terbuka jika jawaban benar skor 1 dan jawaban tidak tahu atau salah skor 0. Penilaian pertanyaan tertutup jika benar bernilai 1 dan salah bernilai 0 . Analisis data yang digunakan adalah analisis univariat untuk menggambarkan nilai mean, median, minimal, maksimal dan standar deviasi. Untuk mengetahui pengaruh pengetahuan terhadap keterlambatan digunakan analisis regresi linier.

\section{HASIL}

Dari total 58 anggota keluarga pasien rata-rata berusia 45,38 tahun (SD. 11,46), didominasi perempuan, dengan tingkat pendidikan SD dan merupakan anak dari pasien. Sebagian besar responden menyatakan tidak 
mendapatkan informasi. Dari mereka yang mendapatkan informasi, dokter masih menjadi sumber informasi terbesar sesudah keluarga atau saudara dan sumber yang tidak jelas. Menunggu dan membiarkan masih menjadi respon terbesar (32,8\%), disamping segera dibawa ke instalasi gawat darurat. Respon lainnya adalah segera membawa ke petugas kesehatan dengan perawat dan bidan menjadi pilihan terbanyak, diikuti dokter atau Puskesmas (Tabel 1).

Gambaran Pengetahuan tentang Faktor Risiko Stroke dan Peringatan Gejala Stroke

Hipertensi merupakan faktor risiko stroke yang paling banyak disebutkan oleh responden. Disamping itu, hiperlidemia, diabetes mellitus dan kurang aktifitas juga merupakan faktor risiko yang banyak diketahui (45-48\%). Beberapa faktor risiko lain yang juga diketahui responden adalah merokok, riwayat penyakit jantung, kegemukan, dan riwayat keluarga dengan stroke, serta konsumsi alkohol (Tabel 2).
Tabel 2. Pengetahuan responden tentang faktor risiko stroke

\begin{tabular}{lrr}
\hline Pengetahuan faktor risiko stroke & $\mathbf{n = 5 8}$ & \% \\
\hline Hipertensi & 43 & 74,1 \\
Hiperlipidemia & 28 & 48,3 \\
Diabetes mellitus & 27 & 46,5 \\
Kurang aktivitas & 26 & 44,8 \\
Merokok & 20 & 34,5 \\
Riwayat penyakit jantung & 20 & 34,5 \\
Denyut jantung tidak teratur & 20 & 34,5 \\
Kegemukan & 18 & 31 \\
Riwayat keluarga dengan stroke & 17 & 29,3 \\
Konsumsi alkohol & 14 & 24,1 \\
\hline
\end{tabular}

Sumber: Data primer (2016)

Hasil penelitian menunjukkan bahwa kelemahan pada salah satu sisi tubuh merupakan gejala peringatan dini yang paling banyak disebutkan responden, diikuti kesulitan bicara atau ketidakjelasan dan gangguan saat berjalan. Meskipun tidak besar, kebingungan, nyeri kepala,

Tabel 1. Karakteristik umum responden anggota keluarga pasien post serangan stroke iskemik akut di instalasi gawat darurat RSUD Ngudi Waluyo Wlingi

\begin{tabular}{|c|c|c|c|}
\hline Karakteristik & & Jumlah & $\%$ \\
\hline Usia & & $45,38^{*}$ & $11,457^{*}$ \\
\hline \multirow[t]{2}{*}{ Jenis kelamin } & Perempuan & 32 & 55,2 \\
\hline & Laki-laki & 26 & 44,8 \\
\hline \multirow[t]{4}{*}{ Tingkat Pendidikan } & SD & 27 & 46,5 \\
\hline & SMP & 13 & 22,4 \\
\hline & SMA & 12 & 20,7 \\
\hline & PT & 6 & 10,4 \\
\hline \multirow[t]{5}{*}{ Pekerjaan } & Tidak bekerja & 29 & 50 \\
\hline & Petani & 18 & 31 \\
\hline & Wiraswasta & 5 & 8,6 \\
\hline & Guru & 5 & 8,6 \\
\hline & PNS & 1 & 1,8 \\
\hline \multirow[t]{5}{*}{ Hubungan dengan penderita } & Anak & 29 & 50 \\
\hline & Istri & 15 & 25,9 \\
\hline & Suami & 6 & 10,3 \\
\hline & Cucu & 4 & 6,9 \\
\hline & Saudara & 4 & 6,9 \\
\hline \multirow[t]{2}{*}{ Mendapatkan informasi } & Tidak & 30 & 51,7 \\
\hline & Ya & 28 & 48,3 \\
\hline \multirow[t]{11}{*}{ Sumber informasi } & Dokter & 13 & 23,2 \\
\hline & Keluarga/saudara & 12 & 21,4 \\
\hline & Dari mulut ke mulut & 11 & 19,6 \\
\hline & Perawat/bidan & 6 & 10,7 \\
\hline & Internet & 5 & 8,9 \\
\hline & Majalah/koran/buku & 4 & 7,1 \\
\hline & Rumah sakit & 2 & 3,6 \\
\hline & Televisi & 1 & 1,8 \\
\hline & Radio & 1 & 1,8 \\
\hline & Sumber lainnya & 1 & 1,8 \\
\hline & Pegawai obat/apoteker & 0 & 0 \\
\hline \multirow[t]{9}{*}{ Respon } & Menunggu dan membiarkan & 19 & 32,8 \\
\hline & Segera ke instalasi gawat darurat & 12 & 20,7 \\
\hline & Memanggil perawat/bidan dan membawa berobat ke perawat/bidan & 10 & 17,2 \\
\hline & Membawa ke dokter praktek & 6 & 10,3 \\
\hline & Membawa ke puskesmas & 5 & 8,6 \\
\hline & Menghubungi keluarga/tetangga terdekat & 2 & 3,4 \\
\hline & Rujukan rumah sakit terdekat & 2 & 3,4 \\
\hline & Memanggil dokter & 1 & 1,8 \\
\hline & Membawa ke pengobatan tradisional & 1 & 1,8 \\
\hline Total & & 58 & 100 \\
\hline
\end{tabular}


kesemutan, kelemahan pada satu sisi wajah, dan gangguan penglihatan juga disebutkan responden sebagai gejala peringat stroke (Tabel 3 ).

Tabel 3. Pengetahuan responden tentang peringatan gejala stroke

\begin{tabular}{lrr}
\hline & $\mathbf{n = 5 8}$ & $\mathbf{\%}$ \\
\hline Kelemahan pada salah satu sisi tubuh & 37 & 63,8 \\
Kesulitan berbicara atau bicara tidak jelas & 31 & 53,4 \\
Gangguan saat berjalan & 31 & 53,4 \\
Kehilangan keseimbangan saat berjalan & 27 & 46,6 \\
Kebingunggan (confusion) & 22 & 37,9 \\
Nyeri kepala berat & 20 & 34,5 \\
Kesemutan pada salah satu sisi tubuh & 19 & 32,8 \\
Kelemahan pada salah satu sisi wajah & 18 & 31 \\
Gangguan penglihatan & 11 & 20 \\
\hline
\end{tabular}

Sumber: Data primer(2016)

Secara keseluruhan, skor pengetahuan anggota keluarga penderita stroke adalah 8,55 dengan variasi yang cukup tinggi (SD.4,55). Rerata keterlambatan kedatangan pasien di IRD adalah 23 jam 12 menit dengan maksimal keterlambatan mencapai 69 jam (Tabel 4).

Tabel 4. Analisis univariat pengetahuan dan keterlambatan kedatangan pasien post serangan stroke iskemik akut

\begin{tabular}{lcccc}
\hline \multicolumn{1}{c}{ Variabel } & $\mathbf{n}$ & Mean & Std. Deviasi & $\begin{array}{c}\text { Median } \\
\text { (minimum- } \\
\text { maksimum) }\end{array}$ \\
\hline $\begin{array}{l}\text { Pengetahuan } \\
\text { Keterlambatan }\end{array}$ & 58 & 8,55 & 4,551 & $8(2-21)$ \\
\hline
\end{tabular}

Sumber: Data primer (2016)

Pengaruh Pengetahuan tentang Faktor Risiko dan Peringatan Gejala Stroke terhadap Keterlambatan Kedatangan Pasien Post Serangan Stroke Iskemik Akut di IGD RSUD Ngudi Waluyo Wlingi

Gambaran waktu kedatangan di IRD dan rerata pengetahuan anggota keluarga menunjukkan kecenderungan bahwa semakin rendah pengetahuan keluarga pasien semakin lama keterlambatan kedatangan pasien stroke di IGD (Tabel 5). Sebagai contoh pada pasien dengan kedatangan ke IGD dalam 0-3 jam, tingkat pengetahuan keluarganya sebesar 12,6 (SD. 3,36), lebih tinggi bila dibandingkan dengan pasien yang datang lebih dari 48 jam, mempunyai tingkat pengetahuan 5,6 (SD. $5,2)$.

Tabel 5. Pengetahuan tentang faktor risiko dan peringatan gejala stroke berdasarkan waktu kedatangan

\begin{tabular}{lrr}
\hline Waktu Kedatangan & $\mathbf{n ~ ( 5 8 )}$ & Rerata \pm SD Pengetahuan \\
\hline 0-3 jam & 7 & $12,6 \pm 3,36$ \\
3-6 jam & 9 & $9,0 \pm 4,12$ \\
6-24 jam & 21 & $13,4 \pm 3,85$ \\
24-48 jam & 5 & $6,0 \pm 1,58$ \\
>48 jam & 16 & $5,6 \pm 1,52$ \\
\hline Sumber: Data primer (2016) & &
\end{tabular}

Sumber: Data primer (2016)
Hasil analisis regresi linier didapatkan bahwa pengetahuan tentang faktor risiko dan peringatan gejala stroke berpengaruh terhadap keterlambatan kedatangan pasien post serangan stroke iskemik akut di Instalasi Gawat Darurat RSUD Ngudi Waluyo Wlingi $(r=0,303 ; p=0,041)$

\section{DISKUSI}

Hasil penelitian ini menunjukkan bahwa pengetahuan berpengaruh terhadap keterlambatan kedatangan pasien post serangan stroke iskemik akut di Instalasi Gawat Darurat RSUD Ngudi Waluyo Wlingi. Hasil penelitian ini juga menunjukkan bahwa rata-rata (mean) skor pengetahuan responden adalah 8,55 \pm SD 4,551, sebanyak $62,07 \%$ mempunyai skor pengetahuan di bawah rata-rata $(<8,55)$ yang menunjukkan bahwa sebagian besar responden mempunyai pengetahuan yang kurang tentang faktor risiko dan peringatan gejala stroke yang dapat menyebabkan responden tidak segera membawa pasien ke rumah sakit atau instalasi gawat darurat. Hal tersebut ditunjukkan $87,9 \%$ responden datang ke instalasi gawat darurat $>3$ jam setelah serangan stroke dengan rata-rata keterlambatan kedatangan 23 jam 12 menit.

Temuan ini sesuai dengan penelitian Philip-Ephraim (18) di Nigeria, Pinzon (21), Siddiqui (29) dan Jones (30) yang menyatakan bahwa sebagian besar pasien datang lebih dari 24 jam setelah serangan stroke ke rumah sakit karena kurangnya pengetahuan tentang gejala stroke sehingga tidak mengenali gejala yang ada dan tidak segera berespon membawa pasien ke instalasi gawat darurat. Kurangnya pengetahuan tersebut akan menyebabkan ketidakmampuan mengenali gejala stroke, salah penafsiran terhadap gejala yang terlihat sehingga mengganggap gejala yang ada bukan suatu hal yang serius, berharap gejala hilang dan tidak segera memanggil Emergency Medical Service atau membawa ke instalasi gawat darurat (31). Sebuah studi juga menyatakan bahwa seseorang yang mempunyai pengetahuan yang kurang tentang faktor risiko, peringatan gejala stroke dan ketidakpahaman tentang konsep "time is brain"akan terlambat dalam merespon stroke sebagai kondisi gawat darurat yang memerlukan penanganan segera sehingga semakin memperlama kedatangan ke rumah sakit atau mencari bantuan kesehatan (12).

Pengetahuan stroke terbagi menjadi dua hal yaitu pengetahuan tentang faktor risiko dan peringatan gejala stroke merupakan dasar untuk menerapkan pencegahan yang efektif dan mendapatkan penanganan awal dengan segera $(32,33)$. Pengetahuan tentang faktor risiko stroke sangat penting untuk meningkatkan kesadaran dalam rangka pencegahan stroke baik primer maupun sekunder sehingga individu mampu mengubah atau memodifikasi faktor risiko, dengan demikian akan menurunkan risiko stroke atau penyakit kardiovaskuler yang lain, menurunkan biaya perawatan dan mencegah terjadinya kecacatan. Pengetahuan tentang gejala stroke ini sangat penting untuk mengenali adanya serangan stroke dan konsekuensinya pasien segera ke instalasi gawat darurat atau rumah sakit. Diharapkan individu yang mempunyai pengetahuan tentang gejala stroke akan menyadari atau mengenali gejala yang ada untuk segera mencari bantuan kesehatan dan mengurangi keterlambatan (32).

Menurut Notoatmodjo dan Sunaryo pengetahuan adalah aspek intelektual yang diketahui manusia. Pengetahuan yang merupakan hasil penginderaan seseorang terhadap 
suatu objek tertentu melalui indra yang dimilikinya adalah salah satu faktor yang sangat penting untuk terbentuknya tindakan seseorang (overt behaviour) $(23,34)$. Perilaku yang didasari oleh pengetahuan akan lebih langgeng daripada perilaku yang tidak didasari pengetahuan sehingga pengetahuan disini adalah menjadi dasar dalam merubah perilaku sehingga perilaku itu langgeng (34).

Perubahan atau adopsi perilaku baru adalah suatu proses kompleks dan memerlukan waktu yang relatif lama. Secara teori perubahan perilaku seseorang dalam kehidupannya terdapat 3 tahapan yaitu pengetahuan, sikap dan praktik atau tindakan. Sebelum seseorang mengadopsi perilaku (berperilaku baru) maka harus tahu terlebih dahulu apa arti atau manfaat perilaku tersebut bagi dirinya atau keluarganya. Setelah seseorang mengetahui stimulus atau objek tersebut maka proses selanjutnya adalah melakukan penilaian atau bersikap terhadap stimulus atau objek kesehatan tersebut sesuai apa yang diketahuinya dan selanjutnya diharapkan akan melaksanakan atau mempraktikkan apa yang diketahui atau disikapinya. Inilah yang dinamakan praktik kesehatan atau perilaku kesehatan (34). Pengetahuan ini akan muncul berupa perilaku manakala ada keadaan yang sesuai yang dapat memicu atau mendorong munculnya perilaku tersebut, sehingga dapat dikatakan bahwa adanya perubahan pengetahuan pada seseorang akan memfasilitasi perubahan perilaku seseorang tersebut $(30,35)$.

Mempraktekkan pengetahuan tentang peringatan gejala stroke yang dimiliki pada tindakan yang nyata merupakan suatu hal yang sangat penting untuk menurunkan keterlambatan kedatangan (36). Peningkatan pengetahuan pasien atau keluarga tentang stroke akan meningkatkan waktu reaksi dan kedatangan pasien ke rumah sakit (21). Hasil penelitian ini menunjukkan bahwa semakin baik pengetahuan seseorang atau anggota keluarga tentang faktor risiko dan gejala stoke maka seseorang itu akan segera merespon atau menilai suatu stimulus atau objek yang berupa faktor risiko dan gejala stroke dengan segera membawa pasien ke fasilitas kesehatan atau mencari bantuan kesehatan. Pasien yang datang tepat waktu ke rumah sakit membutuhkan pengetahuan yang baik tentang faktor risiko dan peringatan gejala stroke dan mampu mempraktekkan pengetahuan yang dimiliki dalam tindakan (32).

Responden yang membawa pasien datang ke instalasi gawat darurat dalam 0-3 jam setelah serangan stroke, mempunyai pengetahuan yang baik tentang faktor risiko dan peringatan gejala stroke. Hal ini sejalan dengan penelitian Alhazzani (37) yang menyebutkan bahwa pasien yang mempunyai pengetahuan tentang gejala stroke akan datang lebih cepat ke instalasi gawat darurat dibandingkan dengan yang kurang mempunyai pengetahuan tentang gejala stroke. Pengetahuan yang baik tentang stroke ini bukan hanya berkontribusi terhadap kedatangan awal ke instalasi gawat darurat akan tetapi juga berkontribusi dalam meningkatkan aktivasi EMS dan menggunakan transportasi ambulan gawat darurat ke instalasi gawat darurat yang semakin memperpendek kedatangan dari onset stroke $(38,39)$. Perbedaan tingkat pengetahuan seseorang akan mempengaruhi perbedaan waktu kedatangan ke rumah sakit (40).
Penelitian Kim (38) dan Teuschl \& Brainin (41) menjelaskan bahwa pengetahuan tentang stroke oleh keluarga/ saudara/ bystander lebih penting dibandingkan oleh pasien sendiri dengan alasan keluarga/saudara/ bystander yang mempunyai pengetahuan baik tentang stroke jika menemui gejala stroke akan segera mengenali gejala yang ada dan mengambil keputusan untuk memanggil EMS atau segera ke instalasi gawat darurat dibandingkan dengan apabila pengetahuan itu dimiliki oleh pasien. Berbeda jika keluarga tidak mempunyai pengetahuan yang baik akan terlambat mengenali dan mengambil keputusan untuk segera ke IGD. Penelitian ini menemukan bahwa responden yang mengetahui dan terlibat langsung membawa pasien ke IGD adalah anak, dengan rata-rata pengetahuan yang kurang tentang faktor risiko dan peringatan gejala stroke sehingga sebagian besar terlambat membawa pasien ke IGD.

Hal berbeda dikemukan oleh Reeves (42) yang menyatakan bahwa tidak ada pengaruh antara tingkat pengetahuan dengan ketepatan kedatangan pasien ke instalasi gawat darurat karena peningkatan pengetahuan seseorang tentang stroke tidak selalu meningkatkan action seseorang tersebut. Peningkatan pengetahuan ini juga tidak selalu merubah perilaku seseorang untuk mengurangi faktor risiko dan melakukan tindakan yang tepat ketika terjadi stroke. Pengetahuan yang baik tentang faktor risiko dan peringatan gejala stroke tidak selalu membuat seseorang mampu mengenali gejala stroke apabila menemui pada situasi yang nyata (43). Penelitian sebelumnya menunjukkan bahwa meskipun sebagian besar pasien mempunyai pengetahuan baik tentang gejala stroke akan tetapi karena pemahaman yang kurang mengakibatkan $76,9 \%$ pasien mengalami kesulitan untuk menginterpretasikan atau mengenali gejala yang ada sebagai gejala stroke atau merupakan suatu keadaan darurat yang memerlukan tindakan segera (44).

Proses suatu pengetahuan sampai terjadi action atau tindakan yang tepat ini terdiri dari beberapa tahapan yaitu mempunyai pengetahuan yang baik tentang peringatan gejala stroke, mampu mengenali dan menginterpretasikan peringatan gejala yang ada pada situasi nyata, kesadaran untuk segera mengaktivasi layanan gawat darurat (EMS) dan membawa ke instalasi gawat darurat. Untuk terjadi suatu action harus didukung oleh keempat hal tersebut yang tidak terpisahkan, apabila salah satu dari keempat tahapan tersebut tidak terpenuhi maka pengetahuan yang dimiliki tidak membuat seseorang melakukan action yang tepat saat terjadi stroke (36).

Pengetahuan yang dimiliki seseorang tentang faktor risiko dan peringatan gejala stroke ini dipengaruhi oleh beberapa faktor antara lain pendidikan, usia, pekerjaan dan sumber informasi yang didapatkan sebelumnya tentang stroke. Pada penelitian ini sebagian besar responden (62,07\%) mempunyai skor pengetahuan di bawah rata-rata (mean), yang menunjukkan bahwa mempunyai pengetahuan yang kurang tentang gejala stroke. Keadaan ini dapat dipengaruhi oleh berbagai hal, antara lain tingkat pendidikan seseorang. Sebagian besar responden $(46,5 \%)$ berpendidikan sekolah dasar (SD) dan hanya $10,4 \%$ yang berpendidikan perguruan tinggi. Pendidikan ini mempengaruhi cara pandang seseorang terhadap informasi baru yang diterimanya dan mempengaruhi perilaku seseorang untuk termotivasi melakukan sesuatu yang lebih baik (45). Adanya pendidikan akan memudahkan seseorang menyerap dan memahami 
pengetahuan yang diperoleh sehingga diharapkan akan semakin bertambah pengetahuannya (34). Selain itu pendidikan terutama yang diperoleh secara formal akan lebih mengeksplore dan memudahkan akses untuk mendapatkan informasi tentang stroke sehingga memungkinkan pengetahuan yang dimiliki lebih baik (45).

Rata-rata usia responden anggota keluarga pasien stroke adalah 45 tahun dengan standar deviasi 11,457. Notoatmodjo (34) menyebutkan bahwa usia mempengaruhi daya tangkap dan pola pikir seseorang. Semakin bertambah usia akan semakin berkembang pula daya tangkap dan pola pikirnya, sehingga pengetahuan yang diperolehnya semakin membaik terutama pada usia madya yang lebih banyak waktu untuk membaca, berperan aktif dalam kehidupan masyarakat dan sosial. Berbeda dengan fakta penelitian ini meskipun responden sebagian besar pada usia rata-rata 45 tahun tetapi mempunyai pengetahuan yang kurang tentang stroke. Keadaan tersebut bisa karena sebagian besar tidak bekerja atau bertani disamping wilayah Kabupaten Blitar sebagian besar adalah pedesaan dengan sumber informasi minim tentang stroke. Sejalan dengan fakta penelitian ini bahwa 51,7\% responden tidak pernah mendapatkan informasi tentang stroke sebelumnya.

Lebih dari separuh responden belum pernah mendapatkan informasi tentang stroke sebelumnya. Informasi yang diberikan berulang-ulang, pesan yang jelas disampaikan dan hanya berfokus terhadap suatu hal akan membentuk opini baru untuk terbentuknya pengetahuan (46). Adanya paparan informasi yang berulang-ulang menyebabkan individu menerima beragam informasi secara terus menerus dan akan menggabungkan informasi tersebut sehingga membentuk pengetahuan,

\section{DAFTAR PUSTAKA}

1. Biswas M, Sen S, and Simmons J. Etiology and Risk Factors of Ischemic Stroke in Indian-American Patients from a Hospital-Based Registry in New Jersey, USA. Neurology Asia. 2009; 14(2): 81-86.

2. Sweileh WM, Sawalha AF, Al-Aqad SM, Zyoud SH, and Al-Jabi SW. Predictors of in-Hospital Mortality after Acute Stroke: Impact of Gender. International Journal of Clinical and Experimental Medicine. 2009; 2(1): 41-47.

3. Kumar AJ, Nambiar V, Vaidynathan, et al. Stroke Progression. Universal Journal of Medical Science. 2015; 3(3): 60-64.

4. Mozaffarian D, Benjamin E, Go AS, et al. Heart Disease and Stroke Statistics-2015 Update A Report from the American Heart Association. Circulation. 2015; 131: e29-e322.

5. Johnston SC, Mendis S and Mathers CD. Global Variation in Stroke Burden and Mortality: Estimates from Monitoring, Surveillance and Modelling. Lancet Neurology. 2009;8:345-354

6. Yayasan Stroke Indonesia. Indonesia Tempati Urutan Pertama Didunia dalam Jumlah Terbanyak Penderita Stroke. (Online) 04 Agustus 2009. di http://www.yastroki.or.id/read.php?id=341. [diakses tanggal 26 Januari 2016]

7. World Health Organization. World Health Rankings ketrampilan dan sikap yang pada akhirnya juga membentuk perilaku seseorang (34). Fogle (47) menyebutkan bahwa pendidikan kesehatan kepada masyarakat awam dengan radio, televisi dan koran atau majalah terbukti meningkatkan pengetahuan dan kesadaran pasien tentang peringatan gejala stroke pada usia diantara 45 tahun atau lebih tua. Dengan memberikan pendidikan kesehatan tentang stroke menggunakan media massa dapat meningkatkan pengetahuan dan kesadaran masyarakat awam tentang stroke sehingga meningkatkan kedatangan awal pasien ke instalasi gawat darurat untuk segera mendapatkan tindakan (46). Pemanfaatan komunikasi media massa yang dilakukan berulang-ulang akan menyebabkan seseorang mengingat hal yang disampaikan dan mendapatkan ide, gagasan, atau pesan yang baru sehingga meningkatkan pengetahuan yang dimiliki, terutama penggunaan media televisi, radio dan koran atau majalah (48). Pemberian informasi tentang stroke ini juga dapat dilakukan dengan memanfaatkan teknologi informasi yang sedang berkembang yaitu media sosial melalui internet, website, facebook, blog, pesan whatshapp dan twitter. Penggunaan media social ini lebih efektif, efisien, meningkatkan akses informasi kesehatan, berpengaruh positif terhadap peningkatan pengetahuan dan perubahan perilaku serta dapat menjangkau masyarakat secara lebih luas (49).

Penelitian ini membuktikan bahwa kurangnya pengetahuan anggota keluarga berpengaruh terhadap lambatnya respon untuk segera mengambil tindakan membawa pasien ke IGD. Rendahnya pengetahuan ini dipengaruhi rendahnya tingkat pendidikan dan tidak adanya informasi tentang stroke sebelumnya.

Live Longer Live Better. (Online) 2014. di http://www.worldlifeexpectancy.com/countryhealth-profile/indonesia. [di akses tanggal 20 Juli 2016]

8. Global Burden of Diseases, Injuries, and Risk Factors Study 2010. The Global Burden of Disease Study Profile: Indonesia. Seattle, USA: Institute for Health Metrics and Evaluation. 2010: pp. 1-4

9. Suryati T. Beban penyakit Stroke di Indonesia DALYS Lost dengan Analisis Kontrafaktual Faktor Risiko Utama. [Disertasi]. Universitas Indonesia, Jakarta. 2013.

10. Aly Z, Abbas K, Kazim SF, et al. Awareness of Stroke Risk Factors, Signs and Treatment in a Pakistani Population. The Journal of the Pakistan Medical Association. 2009; 59(7): 495-499.

11. Putu N, Widayu A, Irbantoro D. Unit Stroke di Rumah Sakit: Arti Penting dan Model Pelayanan. Jurnal Kedokteran Brawijaya. 2016; 29(3): 273-278.

12. Duque AS, Fernandes L, Correia AF, et al. Awareness of Stroke Risk Factors and Warning Signs and Attitude to Acute Stroke. International Archives of Medicine. 2015; 8(195): 1-18.

13. Yang $\mathrm{H}$, Zhang J, Xie J, et al. Factors Influencing PreHospital Delay Among Acute Ischemic Stroke Patients in the Midlands of China. International Journal of Cardiology. 2014; 172(2): 533-534. 
14. Fang J, Yan W, Jiang GX, Li W, and Cheng Q. Time Interval between Stroke Onset and Hospital Arrival In Acute Ischemic Stroke Patients in Shanghai, China. Clinical Neurology and Neurosurgery. 2011; 113(2): 85-88.

15. Fonarow GC, Smith EE, Saver JL, et al. Timeliness of Tissue-Type Plasminogen Activator Therapy in Acute Ischemic Stroke: Patient Characteristics, Hospital Factors, and Outcomes Associated with Door-ToNeedle Times Within 60 Minutes. Circulation. 2011; 123(7): 750-758.

16. Lees $\mathrm{KR}$, Bluhmki $\mathrm{E}$, von Kummer $\mathrm{R}$, et al. Time to Treatment with Intravenous Alteplase and Outcome in Stroke: An Updated Pooled Analysis of ECASS, ATLANTIS, NINDS, and EPITHET Trials. The Lancet Neurology. 2010; 375(9727): 1695-1703.

17. Menon B, Swaroop JJ, Deepika HK, Conjeevaram J, and Munisusmitha K. Poor Awareness of Stroke-A Hospital-Based Study from South India: An Urgent Need for Awareness Programs. Journal of Stroke and Cerebrovascular Diseases. 2014; 23(8): 2091-2098.

18. Philip-Ephraim EE, Charidimou A, Otu AA, Eyong EK, Williams UE, and Ephraim RP. Factors Associated with Prehospital Delay Among Stroke Patients in a Developing African Country. International Journal of Stroke. 2015; 10(4): E39.

19. De Silva DA, Ong S, Elumbra D, Wong MC, Chen CL, and Chang HM. Timing of Hospital Presentation after Acute Cerebral Infarction and Patients' Acceptance of Intravenous Thrombolysis. Annals of the Academy of Medicine Singapore. 2007; 36(4): 244-246.

20. Centers for Disease Control and Prevention (CDC). Prehospital and Hospital Delays After Stroke Onset United States, 2005-2006. Morbidity and Mortality Weekly Report. 2007; 56(19): 474-478.

21. Pinzon R. Mengapa Pasien Stroke Datang Terlambat ke Rumah Sakit? Medicinus. 2012; 25(1): 18-23.

22. Memis S, Tugrul E, Evci ED, and Ergin F. Multiple Causes for Delay in Arrival at Hospital in Acute Stroke Patients in Aydin, Turkey. BioMed Central Neurology. 2008; 8: 1-6.

23. Sunaryo. Psikologi untuk Keperawatan. Jakarta: EGC; 2013.

24. Das S and Das SK. Knowledge, Attitude and Practice of Stroke in India Versus Other Developed and Developing Countries. Annals of Indian Academy of Neurology. 2013; 16(4): 488-493.

25. Song D, Tanaka E, Lee K, et al. Factors Associated with Early Hospital Arrival in Patients with Acute Ischemic Stroke. Journal of Stroke. 2015; 17(2): 159-167.

26. Fassbender K, Balucani C, Walter S, Levine SR, Haass A, and Grotta J. Streamlining of Prehospital Stroke Management: The Golden Hour. The Lancet Neurology. 2013; 12(6): 585-596.

27. Kim YD, Song D, Kim EH, et al. Long-Term Mortality According to the Characteristics of Early Neurological Deterioration in Ischemic Stroke Patients. Yonsei Medical Journal. 2014; 55(3):
669-675.

28. Ennen KA and Zerwic JJ. Stroke Knowledge: How is it Impacted by Rural Location, Age, and Gender. Journal of Rural Nursing and Health Care. 2010; 10(1): 9-21.

29. Siddiqui M, Siddiqui SR, Zafar A, and Khan FS. Factors Delaying Hospital Arrival of Patients with Acute Stroke. Journal Pakistan Medical Association. 2008; 58(4): 178-181.

30. Jones SP, Jenkinson AJ, Leathley MJ, and Watkins CL. Stroke Knowledge and Awareness: An Integrative Review of the Evidence. Age and Ageing. 2010; 39(1): 11-22.

31. Faiz KW, Sundseth A, Thommessen B, and Ronning OM. Factors Related to Decision Delay in Acute Stroke. Journal of Stroke and Cerebrovascular Diseases. 2014; 23(3): 534-539.

32. Faiz KW. Prehospital Delay and Patient Knowledge in Acute Cerebrovascular Disease. [Disertation]. University of Oslo, Oslo. 2014.

33. Gongora-Rivera F, Gutierrez-Jimenez E, and Zenteno MA: GEPEVC Investigators. Knowledge of Ischemic Stroke among a Mexico City Population. Journal of Stroke and Cerebrovascular Disease. 2009; 18 (3): 208-213.

34. Notoatmodjo S. Promosi Kesehatan \& IImu Perilaku Kesehatan. Jakarta: Rineka Cipta; 2007; Hal. 38-209.

35. Johnson D. Behavioral System Model. In: Alligood MR (Ed). Nuring Theorists and Their Work 8 edition. Missouri: Mosby; 2010: pp. 332-355.

36. Fussman C, Rafferty AP, Lyon-Callo S, Morgenstern LB, and Reeves MJ. Lack of Association between Stroke Symptom Knowledge and Intent to Call 911: A Population-Based Survey. Stroke. 2010; 41(7): 15011507.

37. Alhazzani A, Abuhawi O, Aboelyazeed A, Asseri M, and Alshehri A. Does Awareness About Stroke and Stroke Severity Affect Stroke Arrival Time. Journal of the Neurological Sciences. 2015; 357(1): e363-e423.

38. Kim YS, Park S, Bae $\mathrm{H}$, et al. Stroke Awareness Decreases Prehospital Delay after Acute Ischemic Stroke in Korea. BioMed Central Neurology. 2011; 11: 2.

39. Jae JL, Kim HW, and Kim JH. Influence of Stroke Knowledge on Pre-hospital Delay of Acute Ischemic Stroke Patients. Journal of the Korean Neurological Association. 2009; 27(2): 123-128.

40. Lee SH, Lee YW, Kim HS, and Lim JY. Factors Influencing the Hospital Presentation Time of Stroke Patients. Korean Journal of Adult Nursing. 2007; 19(2): 167-177.

41. Teuschl $\mathrm{Y}$ and Brainin M. Stroke Education: Discrepancies Among Factors Influencing Prehospital Delay and Stroke Knowledge. International Journal of Stroke. 2010; 5(3): 187-208.

42. Reeves MJ. Reducing the Delay between Stroke Onset and Hospital Arrival: Is It an Achievable Goal? Journal of the American Heart Association. 2012; 1(3): 
e002477.

43. Sullivan $\mathrm{K}$ and Katajamaki A. Stroke Education: Retention Effects in Those at Low- and High-Risk of Stroke. Patient Education and Counseling. 2009; 74(2): 205-212.

44. Zerwic J, Hwang SY, and Tucco L. Interpretation of Symptoms and Delay in Seeking Treatment by Patients Who Have Had a Stroke: Exploratory Study. Heart \& Lung. 2007; 36(1): 25-34.

45. Obembe AO, Olaogun MO, Bamikole AA, Komolafe MA, and Odetunde M. Awareness of Risk Factors and Warning Signs of Stroke in a Nigeria University. Journal of Stroke and Cerebrovascular Diseases. 2014; 23(4): 749-758.

46. Hodgson C, Lindsay P, and Rubini F. Can Mass Media
Influence Emergency Department Visits for Stroke? Stroke Stroke. 2007; 38(7): 2115-2122.

47. Fogle CC, Oser CS, Troutman TP, et al. Public Education Strategies to Increase Awareness of Stroke Warning Signs and the Need to Call 911. Journal of Public Health Management and Practice. 2008; 14(3): e17-e22.

48. Fogle CC, Oser CS, McNamara MJ, Helgerson SD, Gohdes D, and Harwell TS. Impact of Media on Community Awareness of Stroke Warning Signs: A Comparison Study. Journal of Stroke and Cerebrovascular Diseases. 2010; 19(5): 370-375.

49. Dumbrell D and Steele R. Social Media Technologies for Achieving Knowledge Management Amongst Older Adult Communities. Procedia-Social and Behavioral Sciences. 2014; 147: 229-236 